\title{
A Sociological Analysis on the Survival Strategies of Illegal Urban Transport Operators in Harare Zimbabwe
}

\section{Norman Makunika}

Dibrugarh University Department of Sociology, Dibrugarh District, Assam, India

Corresponding author: nmakunika@gmail.com

Received: 12-10-2019

Revised: $18-01-2020$

Accepted: 29-02-2020

\begin{abstract}
This study set out to investigate the survival strategies of illegal transport operators in Harare, using the City- University of Zimbabwe route of Harare. With most studies on this area, mainly focusing on public transport operations under a broader category, this research paid particular attention to the marginalized public transport operators, which are commuter omnibus operators. As such, the study documented crackdown on commuter omnibus operators by the law enforcement agents, and how in return commuter omnibus operators have managed to come up with strategies that deal with this crackdown. Taking a sociological analysis; this study through the use of the structure-agency theory of Giddens, seeks to comprehend the reality faced by commuter omnibus operators in their day to day activities. Taking a qualitative standpoint, this study also gives a critical gaze into the strategies employed by commuter omnibus operators in countering crackdown by law enforcement agents in the City- University of Zimbabwe route. Thus a qualitative research methodology, mainly in-depth interviews, natural observation and secondary data sources, were utilized in the collection of data.
\end{abstract}

Keywords: Survival strategies, illegal transport, Harare, Giddens, interviews

This research aims at studying the general challenges posed by police raids on commuter omnibus operators, operating the City- Mount Pleasant route. It will explore the strategies used by illegal commuter omnibus operators to cope with the challenges posed by the police and city council raids. The research is partly based on the city police crackdown operations on illegal commuter omnibus in the Central Business District (CBD) of Harare and different routes.

\section{Objectives of the study}

\section{General objective}

* To document different raids faced by commuter omnibus operators and the ways of coping with the raids.

\section{Specific objectives}

1. To assess the nature and form of the police raids on commuter omnibus operators.

2. To assess strategies used by commuter omnibus operators to deal with periodic crackdown by law enforcement agents.

3. To determine the behavior of minibus operators in a specific crackdown environment.

\section{Research questions}

This study probed the following questions:

1. What are the challenges faced by commuter omnibus operators against periodic crackdown by law enforcement agents? 
2. What is the form and nature of the crackdown on commuter omnibus operators by law enforcement agents?

3. What are the strategies they use to cope with the challenges of these crackdowns?

\section{Methodology}

This section will be looking at research design, sampling design and sample size, strategies for data collection, data analysis techniques and the ethical considerations of social research.

\section{Research design}

This study is designed under a qualitative paradigm. Denzin and Lincoln (1994:15) defined qualitative research as an inquiry process of understanding based on distinct traditions of inquiry that explore a social or human problem. Qualitative research studies human beings in their natural settings, attempting to make sense of or interpret phenomena in terms of the meanings people bring to them. Qualitative research methods are found well suited in my study because it is rooted in the voices and social experiences of the research participants. Qualitative research method allowed the researcher to identify and understand commuter omnibus operator's experiences in terms of their own definitions and experiences in relation to the structures that govern them. This allowed the researcher to learn from the commuter omnibus operators themselves. It will also examine the experiences of passengers, traffic police, and Vehicle Inspection Department Officers (VID) officials, in their day to day operations to crack down illegal commuter omnibus operations.

\section{Sampling designs and sample size}

The sample population of this study was purposively selected from the target population of commuter omnibus operators at the University of Zimbabwe rank and key informants from the Traffic Police Department. According to Silverman (2000:104) purposive sampling involves the selection of a sample with a particular purpose in mind. Thus my study targeted the University of Zimbabwe Rank area, since there target group of respondents provided the researcher with useful data about the phenomenon under study The researcher purposively selected a sample population of thirty respondents from a group concentration of commuter omnibus operators at the University of Zimbabwe rank area.

The sample size of forty participants, altogether, was selected comprising of ten drivers and ten conductors, together with five key informants from Avondale Police Traffic Department and the other five officers from the City of Harare. Five respondents from the commuters were selected from the pool of passengers. Such research alluded to the reality faced by drivers relative to conductors and passengers since they all have different perceptions on police crackdown on commuter omnibus operations. The sample size was small because of limited resources and time on the part of the researcher.

\section{Strategies for data collection}

This study employed a mix of data collection tools in the data collection process. The methodological tools used to collect data were drawn from primary and secondary sources. The researcher conducted interviews with both drivers and conductors together with officers from the traffic police department. Naturalistic observation was conducted in the form of participant observation, thus the researcher had a deep knowledge of commuter omnibus operators' activities. The primary data collection methods included personal interviews and naturalistic observation in the form of participant observations. Neuman (1997:371) notes that field interviews include a mutual sharing of experiences and the researcher might reveal his or her background to build trust and encourage openness from the respondents. Interviews and observation together with focus group discussions were the main methods that employed for data collection exercise amongst omnibus operators. Thus, combined with naturalistic observation, in-depth interviews and focus group discussion methods allowed the researcher to understand the meanings that everyday activities hold for omnibus operators. In-depth interviews were employed in order to explore in detail the respondent's own accounts. The researcher conducted thirty in-depth interviews, ten with commuter operators, ten, with traffic police officials and ten with passengers Creswell (1994) 
posit that under an 'in-depth' interview the interviewer goes into the field with the aim of discussing a limited number of topics, sometimes as few as one or two, and frames the question on the basis of the interviewee's previous response. Thus this study employed an indepth interview guide for commuter omnibus operators as well as two law enforcement agents, which included a set of core questions which composed the main research focus and aim.

Focus group discussions were conducted with thirty respondents. The researcher divided the respondents in groups of six, meaning that, five focus group discussions were conducted. Denzin (2002) noted that, a focus group discussion allows participants to voice their concerns in a manner that they are comfortable with. It can help reveal some other aspects that the researcher might not have intended to research on whilst enriching his or her data.

Naturalistic observation involves observing participants as they go about their daily activities in real life settings. As a result the study will employed covert naturalistic observation in order to overcome discrepancies between what omnibus operators say in interviews and what they actually do in their real life operations. Thus naturalistic observation allowed the researcher to unravel behavior of which the participants themselves were not aware of. Through naturalistic observations, just as noted by Denzin (2002) in the White corner study, the researcher will be able to develop a rapport with the respondents, thus making it easy to observe the activities that might be difficult to observe under other scenarios.

The secondary data constituted document analysis. The researcher employed this method as it gives a historical outline and allows for an analysis of social interactions based on texts or transcripts. The researcher analyzed various secondary documents such as newspapers and journal articles of historical and contemporary in order to gain insights into the social interactions of omnibus operators based on texts. According to Punch (1995) document analysis, both historical and contemporary, are rich sources of data for social research and they may be collected in conjunction with interviews and observations. Thus the researcher analyzed documents from the News Paper agents such as The Herald, Sunday Mail, News Day and other publications.

\section{Data analysis techniques}

The study is premised under a qualitative paradigm, the researcher employed thematic data analysis as the main tool for data analysis. This involves grouping similar data under one subject or topic. Narrative analysis was also be used in the analysis of data. In analyzing qualitative data, patterns and themes were identified. Theoretical and conceptual frameworks were employed in attaching significance to the patterns and theories identified in the data.

\section{Ethical Consideration}

Researchers have responsibilities to participants when conducting a research. Some of the ethical issues considered in this research are informed consent, confidentiality. The ethic of informed consent mean that the researcher should disclose the purpose of the research and how the information gathered will be used. This also implies that the respondents have a choice whether to participate or not in the research process and their freedom to withdraw from the research anytime they feel uncomfortable with continuing participating.

Participation, without being coerced or unfairly pressurized therefore respondents will be well-informed about what participation entails, and reassured that declining will not affect their lives. Research may pose harm to communities, thus confidentially will be assured by keeping anonymous identities of research respondents and respecting their privacy by not publishing research results in inappropriate ways.

\section{Presentation of Findings}

This chapter will be based on the findings generated through in depth interviews, key informant interviews, focus group discussions and naturalistic observation carried out by the researcher. Thematic presentation of data was used in which the researcher grouped similar data gathered under similar themes. The findings show how structures manifest themselves regarding commuter omnibus operations at the University of 
Zimbabwe rank, and how in turn minibus operators may influence the structures by adopting some coping strategies that maintain police raids. The researcher noted that, the University of Zimbabwe rank is used by both legal and illegal commuter omnibuses, since some operators run their businesses without the required documentation.

The researcher also noted that, the traffic police and the municipality police employ a number of different methods to try and maintain order. They employ a number of different ways to curb the illegal operation of commuter omnibus operators both on the City side of the rank and in the City-University of Zimbabwe route.

\section{Coping strategies employed by commuter omnibus operators against police raids}

\section{Bribery}

Bribery has been highlighted by many respondents as a strategy they use to cope with police raids. The findings show that in most instances, minibus operators are compelled to pay bribes, especially when they are caught loading or off loading passengers in undesignated areas. In such circumstances, the majority of operators acknowledged that they prefer to pay officials five to ten dollars bribes, than to be arrested or clamped by traffic officials and then pay a penalty of up to one hundred and twenty dollars. The majority of the participants were of the view that bribing the law enforcers is better than to be taken to council offices where they lose their money, through fines, or their vehicles through clamping.

\footnotetext{
"Kugara tabhahara chegumi kurinani (chegumi a local slang term referring a ten percent, but in this case it means a ten dollars bribe) panekuyendeswa kumahofisi wonoruza kaviri kuti fine nekukanganiswa basa. (Paying a bribeis better than to be taken to council offices where you are compelled to lose your time and large amounts of money)
}

As enforcers of traffic law, corrupt officials, by accepting bribes, make the jobs of illegal commuter omnibus operators easy, since they easily get away with their illegal operations. One minibus conductor noted during an in-depth interview;

\begin{abstract}
"When the officials catch on us on roadblocks and want to take our vehicle, we have nothing to fear because their roadblocks are simply just like toll gates. If you pay, they will let you go"
\end{abstract}

Though the respondents cited bribing as a strategy, the researcher also found out that there are some instances where minibus operators do not pay bribes to the officials on patrol and road blocks. Asked about the circumstances in which they don't pay bribes, the majority of participants confirmed that when there is a serious operation or when junior traffic officers are accompanied by their seniors, traffic police sometimes reject bribes as their superiors will be closely monitoring their operations. One officer said in an in-depth interview

"I have a job to protect and a family to look after, so I won't risk taking a bribe when I surely know that it might land me in trouble."

\section{Fleeing}

Observation and in depth interviews by the researcher noted that flight from police and council raids was a strategy that commuter omnibus operators used to avoid arrests by law enforcement agent. The researcher observed that, commuter omnibus operators resorted to fleeing the police to avoid arrests. The researcher also observed that minibus operators are always watchful of any sign of danger when conducting their businesses, such that, through horning, shouting, whistling, they are quick to alert each other whenever there is a sign of raiding and arrests taking place.

When asked about how they use fleeing as a strategy one operator responded

"Kana tichishandira mumushika shika tinotogara
takagadzirira kutiza nekuti, police kana kanzuru inogona
kungosvika chero nguva"

This can be literally interpreted as to mean 'when operating in illegal undesignated areas, we are always alert as anytime you can be arrested by the traffic police officials".

The researcher observed that commuter omnibus operators are very resilient in their way of doing business as within a couple of hours after the turmoil, 
they were in full operation, conducting their businesses as usual.

\section{Adaptation to police raids}

Based on field interviews conducted with minibus operators, the respondents indicated that they change their operations in response to external pressure. One driverexplained how they are able to deal with periodic police raids;

".....there is no point in operating when the traffic police are carrying out their raiding operations since there is high risk of losing money, even our vehicles when the police raid on us... in fact, sometimes we park our vehicles until the environment is conducive for us to operate without fear of being arrested."

"Hativanzoita basa pama Mondays nema Fridays apo mapurisa nekanzuru zvinenge zvichinetsa nekusunga vanhu" (We rarely conduct our business during Mondays and Fridays because the traffic police will be on patrol)

Another respondent highlighted that he rarely conducts his business on week-ends, especially on Mondays and Fridays, when most raids are carried out. The respondent acknowledged that this minimizes the danger of being arrested.

Through frequent and close succession of crackdowns, commuter omnibus operators have managed to predict the occurrence of police raids such that they have devised ways to counter them. Thus, through adaptation to police pressure, minibus operators have found new ways of dealing with police raids.

\section{Nocturnal operation (early morning and night)}

From the research interviews conducted with commuter omnibus operators, the researcher found that the most common feature in the behavior of illegal commuter omnibus operators is nocturnal trading, also known as night operations. As observed by the researcher, this method is a direct reaction to police attacks and raids during the day. Illegal minibus operators have resorted to operating early in the morning and late hours starting from sunset to late hours as the municipal officers and the ZRP officers go off duty and cannot arrest them for illegal operations. The majority of the participants highlighted that they no longer operate on the streets during the day; instead they prefer to operate when the situation is quiet and free from law enforcement agents. Revealing this trend of night operation, one respondent recounts;

"Why should I operate during the day when there are many police raids, roadblocks and operations against illegal commuter omnibus operations? Surely I know that I will get arrested"

He added;

"I would rather park my vehicleat home or operate on routes that have few police road blocks during the day time. As the sun sets I start to operate the City-University of Zimbabwe route, where the risk of being arrested is minimal"

Robert (21) reported that since joining illegal commuter operations, he has been able to avoid arrest by the traffic police through night operation.

"Business is brisk for us between $5 \mathrm{pm}$ and as late as 9pm. Why should Irisk getting into town in the afternoon and lose all my permits, license and vehicles from these cruel officers? This is my only means of survival; I would rather operate during the late hours when most of them will be off duty"

This implies that instead of getting arrested or having their vehicles impounded, commuter omnibus operators have embarked on night operations, as most of the traffic police will be off duty. Apart from police absence at night, the researcher observed that, night operation suit those without route permits and operators without proper documentation needed for the operation of public transport as per the Traffic Safety Council requirements.

\section{Route changing}

Through naturalistic observations and focus group discussions, the researcher noted that, route changing is also a strategy used by commuter omnibus operators to cope with Traffic police raids and arrest. In an interview, one operator noted;

"I can easily change the route. It is either, I will use an alternative route to University of Zimbabwe or I will completely change the route and ferry commuters to 
Marlboroughor Vinona so as to avoid police raids and roadblocks"

In a focus group discussion, the respondents seemed to prefer to operate the City-Avondale route where there are few police roadblocks along the route.

In a naturalistic observation, when informed about the police roadblock near Belgravia Shopping centre, one operator changed his route to University of Zimbabwe and resorted using the route via State House and Domboshava road where, he could freely avoid the police.

\section{Nature and form of the crackdown}

This segment presents the nature and forms of crackdowns minibus operators face in their daily operations. Thus, based on thirty field interviews and three weeks of naturalistic observation, a number of findings emerged in the study. Findings indicated that the nature and form of crackdown is often characterized by physical assaults, vehicle impounding, arrests and execution of fines, harassment, windscreen smashing and vehicle clamping. In addition, the majority of the participants highlighted that there are also numerous covert operations, in the form of undercover traffic police who work in plain clothes as observed through naturalistic observation.

A crackdown can be defined as a severe or stern enforcement of regulations to root out abuses or correct a problem. Based on in-depth interviews with commuter omnibus operators and traffic law enforcement agents, the researcher managed to solicit reasons why the law enforcement agents engage in continuous crackdowns on public transport operators. A number of findings pertaining to the nature and form of the crackdown and the reasons for frequent crackdown on public transport operators by the law enforcement personnel emerged. These research findings were jotted down by the researcher and presented in themes below.

\section{Physical assaults}

Having informed by a key informant about days on which the officials normally carry their raids, the researcher witnessed the brutal nature of the law enforcement personnel on minibus operators. The researcher noted some joint operations of the ZRP and the Harare Municipal traffic police against commuter omnibus operators in spirited a attempt to bringing order to the city of Harare. Based on field observations commuter minibus operators were involved in running battles with the police. In the study, a group of minibuses were seen, fleeing police raids on their illegal pick up point on Corner Mbuya Nehanda and Nelson Mandela Street. The officials were fully armed with clamps and batons, chasing, smashing windscreens and impounding vehicles.

Some operators who were interviewed showed great discontent with the official attitude towards their activities. One minibus conductor, said in an interview,

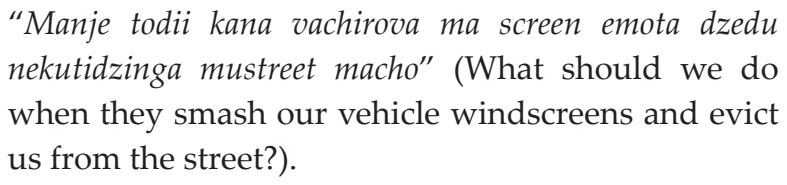
nekutidzinga mustreet macho" (What should we do when they smash our vehicle windscreens and evict us from the street?).

In-depth interviews were conducted with two law enforcement agents, in a bid to understand the motive behind continuous crackdowns on commuter omnibus operators who are trying to pick up passengers in undesignated areas in the city. Findings from these in-depth interviews highlighted that illegal minibus operators infringe on a number of laws and regulations governing them. As such, contravening such laws and regulations compels the enforcement of the law through arrests and physical assaults in order to create order in towns. Asked about why they smash windscreens one female ZRP officer reported:
"Basa redu ndereku maintainer order munyika semapurisa, mahwindi, nemakombianozara dhorobha rese vachikonzera commotion" (It is our obligation as police to maintain order in the country. Touts and minibus operators scattered everywhere in town cause commotion) [Officer 1]

Another respondent, a male municipal police officer also highlighted other reasons for continuous crackdown son commuter omnibus operators,

\footnotetext{
"Makombi, nemahwindi anoita rusha uye anosvibisa tawundi uye vamwe havana malicense ekutakura vanhu, vanongoda kutakura kana kudzikisa vanhu pose pose
} 
pasingatenderwi nemutemo" (Touts and minibus operators causes noise and litter the town and some do not have licenses for operation. Some of them just pick and drop passengers anywhere and everywhere in town, even in places that are dangerous and not permitted by the traffic laws) [Officer 2]

The research further highlighted that some of the places that commuter omnibus operators use as ranks are dangerous and not permitted by laws. One such place is the intersection illegal rank that commuter omnibus operators use to load passengers going to the University of Zimbabwe.

\section{Vehicle Impounding}

The confiscation process involves the lawful seizure vehicles by the authorities or the law enforcement agents. Based on in-depth interviews conducted with commuter omnibus operators, the majority of the participants highlighted that on several occasions the traffic officials had impounded their vehicles, when caught operating on prohibited zones, when parked dangerously, and for picking and dropping passengers on prohibited areas. When a vehicle is impounded, a heavy fine ranging from one hundred and twenty to two hundred dollars will be levied. Commuter omnibus operators confirmed that they are compelled to pay more than the required fine, in addition to their vehicles. Due to this continuous loss of cars and heavy fines, many respondents were in a state of helplessness as their source of livelihood was being destroyed by the law enforcement agents. One participant reported the following in an interview,

"Manje torarama neyi shuwa isu tichizvitsvakira kurarama" (What should we survive on when we are trying to make ends meet?)

Interviews conducted with police officers highlighted that the vehicle impounding practice is in line with laws and regulations governing traffic management. On commuter omnibus activities, the police officers acknowledged that touting and illegal commuter operations infringe the traffic laws as well as the city of Harare traffic by-laws. The police officers acknowledged they are obliged by the law to impound and arrest illegally operating vehicles. Thus, commuter omnibus are not excluded. The impounded vehicles will be put under police control at Harare Central Police Station and other City of Harare depots.

\section{Arrests and execution of fines}

As indicated in the research, arrests and execution of fines have characterized the law enforcement personnel attitudes and reactions to illegal commuter omnibus operators in the city- University of Zimbabwe route. The findings indicates that the most frequently infringed regulations include, operating in prohibited areas, operating without valid licenses and permits, operating with unroad worthy vehicles, overloading vehicles, over speeding, obstruction of traffic and people. As such, arrests take place when commuter omnibus operators infringe on any of the regulations listed above. The research shows that, the majority of commuter omnibus operators' pay heavy spot fines amounting US\$10-20, on a day to day basis. Some commuter omnibus operators have acknowledged that they have created some relationships with many of the officials involved in the roadblocks, raiding and arrests, especially the municipal police, and therefore pay only five dollars bribery fines, thus evading arrest or stopping by police.

In a focus group discussion, one respondent driver noted,

\footnotetext{
"Kana uine ma face ako ku police kana kukanzuru, haumbosweronetswa unoswera uchishanda zvakanaka vozongonobhadhara chebasa manheru". (If you have friends or someone who knows you well in the traffic police department or Harare city council, you have no worries as you can safely pass roadblocks without being stopped and you pay them later).
}

While operating as an observer, on a roadblock, when stopped by the traffic police, one commuter omnibus conductor responded that

\section{"hatisati tashanda officer tinouya tokusotai kana tikamboita mari"}

This can be translated to mean (we are just starting to work officer, we don't have money yet, we will come to pay later)

The researcher observed that, though commuter omnibus operators who are caught on the wrong side 
of the law are made to pay heavy fines at the hands of traffic police, through development of friendships and relationships with traffic officers, they have managed to counter the effects of these fines on their day on day operations.

\section{Covert operations}

As the study indicated, there are numerous covert operations in the form of undercover police in plain clothes. The Newsday, (17/01/14), confirmed that there were multiple covert raids and seizures in the city of Harare which led to the confiscation and impounding of more than five hundred illegally operating commuter omnibuses and illegal private taxis. In such raids, the findings reveal that many commuter omnibus operators are arrested in operations which involve officials from the Traffic Safety Council of Zimbabwe, Zimbabwe Revenue Authority, Zimbabwe Republic Police and the City of Harare Traffic Police Department. Such raids are characterized by undercover policemen dressed in their plain clothes so as to deceive commuter omnibus operators who are then caught unaware. As indicated in the same, News day publication, the undercover operations are a common feature in the CBD of Harare and by January 2014, in an operation which was dubbed the "Hundred Days Operation Blitz' the campaign impounded more than two thousand vehicles from November 2013 to January 2014. Based on the aforementioned insights, the research findings also indicated that, these covert operations target not only commuter omnibuses but all vehicles, both private and public, breaking traffic laws in the City of Harare.

\section{Discussion of Findings}

The aim of this section is to discuss the findings of this study. This will be done in light of the existing literature and using Giddens (1984) structuration theory. This discussion will reveal gaps in existing studies where other scholars have not clearly brought out the challenges faced by commuter omnibus operators and how they mitigate these challenges posed by law enforcement agents to their day to day operations. This study showed that commuter omnibus operators have constrains in their day to day operations, and they have devised a number of strategies to shape their everyday operations. They adopt strategies that enable them to cope and survive under otherwise difficult circumstances.

In the study, a large number of those in the commuter omnibus industry have not joined the industry willingly. Due to the economic hardship experiencing the country, most of them cannot secure formal employment. The research highlighted that, many participants relied on commuter omnibus operation as their full time jobs and as their only source of subsistence. For instance, in this study one respondent outlined that since completing high school in 2010, the commuter omnibus operation business has been his only form of employment and source of income, and his only means of survival. Other respondents also highlighted that commuter omnibus operations are their only means of survival. Dhemba (1999) describes similar findings in his study of the informal sector where the majority commuter omnibus operators emerged as a result of economic hardships since early 2000. Muzondidya (1991) argues that people in Zimbabwe facing a devastating crisis situation had the capacity to transform their existence and were not merely passive recipients of structural arrangements. Thus the commuter omnibus operators in this study were compelled by economic crisis to resort to public transport servicing as their means of earning a living.

Giddens (1984) structuration theory states that structures are constraining to human action. As such, the findings showed that the persistent and protracted raids on commuter omnibus operators are a manifestation of the constraints of structures. In the study, for example, the Municipal police together with the Zimbabwe Republic Police (ZRP) officials embark on constant raids in the urban informal sector targeting commuter omnibus operators. This implies that structures are compelling to individual commuter omnibus operators as they are always in running battles with the law enforcers. The heavy fines imposed on commuter omnibus operators when their vehicles are impounded, and the raids and spot fines also indicate the constraining effects of the structures.

In addition to the afore-mentioned insights, it can be argued that as agents, commuter omnibus operators 
take some action against initiatives which make their lives harder. The study showed that as a way of mitigating crackdowns by the law enforcement agents, commuter omnibus operators have adopted some creative strategies that enabled them to cope and survive these periodic raids. These strategies include bribing the law enforcers with money when they are caught, night operations as a response to daylight harassment, route changing as well as fleeing. Musoni (2010) argues that informal operators are not hopeless victims against structural forces, and demonstrates that these commuter omnibus operators show a high level of sophistication by opting for adaptive resistance.

Moreover, it can be argued that the findings are a manifestation of Giddens' structure agency theory. The theory states that structures are both constraining and enabling, meaning that commuter omnibus operators have the ability to influence structures to their advantage. Muzondidya (2008: 4) also concurs with the above statements by arguing that although there might be constraints on actors from structures, this does not necessarily mean that the actors remain passive. Rather the structures produce new forms of agency and creative strategies. This implies that commuter omnibus operators are not passive recipients of the structures, but are conscious actors in their everyday lives.

Conflicts with certain Municipal officials and other operators within the city of Harare were also noted in the study. The study highlighted that assaults and raids characterize the official attitude and reactions towards commuter omnibus operations. The findings converge with Mitullah's (2005) review of public transport operations in six African countries including Zimbabwe, where she noted that the institutional frameworks governing public transport operations have generally been hostile in many African countries leading to incidences of confrontation between the law enforcement personnel and public transport operators.

It can be argued that some of the commuter omnibus operators' strategies of dealing with crackdown are determined by external stimuli. The research showed that through adapting to police pressure, commuter omnibus operators have managed to adjust and are able to manipulate the situation to their advantage. They have adopted some adaptive resistance to police pressure, such as, developing friendships with traffic police officials, bribing, and route changing and avoiding the use of main roads that usually have roadblocks mounted by traffic police. Musoni (2010) indicated similar findings in his analysis of the survivors of the post Murambatsvina era, where he concluded that the informal traders demonstrated a high level of sophistication and political maturity by opting for adaptive resistance. The research acknowledges that commuter omnibus operators have become aware of the time and days in which the raids and road blocks occur such that they have devised ways of countering these crackdowns. In the study, for example, one of the respondents highlighted that he rarely comes to work in the morning and Fridays, when most raids are carried out. This implies that adaptation to police pressures has helped commuter omnibus operators to manage in their operations notwithstanding the state's effort to combat and thwart their illegal operations. As such, one can argue that illegal commuter omnibus operators are not passive recipients of structural arrangements.

As it emerged from this study, commuter omnibus operators comprise various actors, who employ various strategies and are resilient in the defense of their livelihoods. Violent operations against illegal commuter omnibus operations in the city of Harare have proven not to be an effective remedy to commuter omnibus operators' unlawful practices. As argued by Kamete (2010), the continuation of illegal commuter omnibus operation entails defying and resisting the often violent restoration of order by the authorities. Moreover, Giddens' (1984: 14) structuration theory states that, agents as actors cease to be such if they lose the capacity to make a difference, that is, to exercise some sort of power to a pre-existing state of affairs. Giddens certainly recognizes that there are constraints on actors, but this does not mean that actors do not have strategies to use against these constrains. The study showed that this is the case among illegal commuter omnibus operators, in the city of Harare, where police violence was countered with various strategies. This implies that commuter omnibus operator's capabilities are crucial 
in determining how they cope with different social processes in their social world. As such, it can be argued that the strategies which minibus operators employ in dealing with police crackdowns are determined by their practical consciousness and capabilities to finding ways of shaping their everyday lives. This affirms the point that commuter omnibus operators as agents are not passive victims of structures.

The results of this study are also an appreciation of Giddens structuration theory. The theory states that structures are defined in relation to resources recursively involved in social production. Giddens notes that these resources are allocative and authoritative, where allocative resources include control over material things, whereas authoritative resources include control over people in the form of politics. The latter, concurs with the findings of this study where it is noted that the majority of the illegal commuter omnibus operators are controlled by their lack of documentation and permits, as constrains not to operate during the days where the police raids and road blocks will be in evidence. The study showed that structures have a constraining effect on individuals since illegal commuter omnibus operators are forced not to use the legal ranking zones as their documentation does not permit them to do so.

According to Giddens (1984) actors rationalize their world in their search for a sense of security. In addition to this, Ritzer (2008) posits that by rationalization Giddens results in the development of routines that not only give actors a sense of security but enable them to deal efficiently with their social lives. Musoni (2010) argues that the Murambatsvina informal economy victims realized their limited capacity to confront the armed forces by devising more subtle ways of resistance. This study shows that in search of a sense of security, commuter omnibus operators rationalize their world by adopting some strategies which do not harm their lives. In this study, for example, minibus operators run away from police raids, change routes, avoid using policed roads since they confront traffic officials. As such, running away and route changing gives them a sense of security both in their business and in their social lives. They escape arrests and avoid having their vehicle impounded.

\section{CONCLUSION}

In conclusion, through the application of different research methods, the researcher observed that, commuter omnibus operators as actors that adapt to different constrains and structures of the social structure. They face different challenges to which they apply different strategies.

\section{REFERENCES}

Brown, 2006. Qualitative Research in Social Science. Sage. New York.

Creswell, J.W. 1994. Research Designs: Qualitative and Quantitative Approaches, Sage Publications. Thousand Oaks, CA:.

Cwilliam, K. 2010. Urban Transport in Developing Countries, Institute of Transport. University of Leeds.

Denzin, N.K and Lincoln, Y.S. 1994. Handbook of Qualitative Research, Sage Publications. Thousand Oaks, CA.

Denzin, N.K. 2000. Handbook of Qualitative Research, Sage Publications Thousand Oaks, CA.

Dube C. 2012. The Informal City: Assessing its scope, variants and direction in Harare, Zimbabwe, Global Advanced Research Journal, 3(5).

Giddens, A. 1984. The Constitution of Society, Outline of the Theory of Structuration, Polity Press, Cambridge.

Kamete, A.Y. 2008. Planning Versus Youth: Stamping Out Spatial Unruliness in Harare, International Journal of Disaster Risk Reduction, 39(5): 1721-1733.

Kamete, A.Y. 2010. Defending illicit livelihoods: Youths resistance in Harare's contested spaces. International Journal for Urban and Regional Research, 34(1):55-77.

Maunder, D.A.C. 2007. Travel characteristics of Urban household in Harare, Zimbabwe. Crasthorne. London.

Mudzengerere, F.V. 2013. Sustainable Urban Traffic Management in Third World countries, The case of Bulawayo, Unpublished thesis, NUST. Bulawayo.

Munhande, C. and Matonhodze, L. 2008. An Assessment of the Impact of Operation Murambatsvina (Operation Restore Order) on the Informal Market: A case of Bulawayo Central Business District (CBD) Commuter omnibus Operations, Journal of Sustainable Development in Africa, 10(3): 1520-5509.

Musoni, F. 2010. Operation Murambatsvina and the politics of Informal sector in Zimbabwe. Journal of Southern African Studies, 36(2): 301-317.

Mitullah, W.V. 2005. Public Transport services in African Cities, a synthesis of empirical finding from Kenya, Cote Devoir, Ghana, Zimbabwe, Uganda and South Africa. Paper for the 2005 World Report. 
Muzondidya. J. 2008. Majoni-joni: Survival strategies among Zimbabwean migrants in South Africa. Paper presented at the international conference on political Economies of Displacement in Post 2000 Zimbabwe, University of Witwatersrand (9-11 June). Accessed 8 October 2013.

Neuman, W.L. 1997. Social Research Methods: Qualitative and Quantitative Approaches, Allyn and Bacon, Boston.
Punch, K.F. 1995. Introduction To Social Research, Quantitative and Qualitative Approaches, Second Edition. Sage Publications.

Ritzer, G. 2008. Modern Sociological Theory, seventh edition, McGraw Hill, New York. 